\title{
Practicing Autonomously: A Comparison of Nurses
}

\author{
Joan E. Wood,* Linda Beth Tiedje, $\dagger$ and Ivo $L$. \\ Abraham $\neq$ \\ *Assistant Professor, College of Nursing, Michigan State \\ University, East Lansing, fdoctoral student, School of \\ Nursing, University of Michigan, Ann Arbor, and $\neq$ Director \\ of Research and Assistant Professor, Frances Payne Bolton \\ School of Nursing, Case Westem Reserve University, \\ Cleveland, Ohio
}

\begin{abstract}
Forty-five subjects including community health nurses with baccalaureate nursing degrees, senior-level generic nursing students, and registered nurses in a baccalaureate nursing program were compared on age, years of employment in nursing, and three variables of professional autonomy: nurses' rights and responsibilities, the nurse-patient relationship, and nurses' role in health care delivery. It was predicted that nurses from baccalaureate programs and those practicing in community health nursing would perceive themselves as more autonomous and that age and years of employment in nursing would not appreciably alter perceptions of autonomy. An analysis of variance confirmed the initial prediction at the 0.01 level of significance or better for nurses' rights and responsibilities and their role in health care delivery. A significant negative correlation was obtained between age and nurses' rights and responsibilities for the community health nurses; a significant positive correlation was obtained between years of work experience and nurses' rights and responsibilities for only the registered nurses. This study is perceived as an initial step in a lengthy process aimed at identifying factors that influence nurses' perceptions about professional autonomy.
\end{abstract}

Autonomy is of considerable personal and professional relevance to nurses. Autono-

Address correspondence to: Joan E. Wood, R.N., M.P.H. College of Nursing, Michigan State University, A-230 Life Sciences Building, East Lansing, MI 48824. Telephone: (517) 355-6523. mous nurses are not only autonomous persons, but advocates for clients and professionals able to function independently yet collaboratively in a complex health care environment. The foundational ideas for this study were (1) the development of personal and professional autonomy and (2) the im- 
pact of nurses' perceptions of professional autonomy on their rights and responsibilities, their relationships with clients, and their relationships with other health care providers.

\section{LITERATURE REVIEW}

\section{Development of Personal Autonomy}

One recurring theme in the literature on adult women is poor fit of developmental models to the experiences of women. Freud, Erickson, Kohlberg, even Piaget, and most others focused almost exclusively on the male in proposing models. How and when women become independent and autonomous, and the relationship of their autonomy to other developmental tasks, are burgeoning areas of research (Gilligan, 1982; Straub, 1982). Findings suggest that autonomy may develop later and occur after women complete more relationship oriented developmental tasks.

\section{Development of Professional Autonomy}

The nurse is first and foremost a person. Being a member of a profession thus focuses on the characteristics of the individual (Styles, 1982). The person, self-concept, and ability to function independently are therefore integral to that nurse's behavior as a professional (Simms \& Lindberg, 1978).

Autonomy is routinely identified as one of the main attributes of a profession (Cogan, 1953; Parsons, 1954; Greenwood, 1957; Wilensky, 1964; Johnson, 1972; Ahad, 1981). The American Nurses' Association's code (1976) stated that nurses must assume accountability and responsibility for their individual nursing judgments and actions. More recently, the Association's position statement on nursing and social policy identified three themes: nursing as a duty, nursing as a moral art, and nursing as an autonomous profession (Silva, 1983).

\section{Nurses' Rights and Responsibilities}

A review of the literature reveals an emerging concern regarding the development of professional, accountable, autonomous nursing practice (Mundinger, 1980; Janik, 1984). Professional autonomy implies control of work and the promulgation and regulation of standards (Freidson, 1970; Eldridge \& Levi, 1982). Some authors assert that nursing is not a profession because it lacks autonomy, self-detemination, and selfgovernance (McFarland \& Shiflett, 1979). This perception hampers nursing's ability to develop power and negotiate with other professional groups and organizations.

Professional autonomy is addressed through establishing educational standards and using approaches that socialize nursing students. Kalisch and Kalisch (1982) posed the following questions to help focus on selfdetermination and the ways nursing students are socialized:

1. To what extent are nursing students encouraged to share their views?

2. How are their questions treated?

3. What occurs when students disagree with those in authority?

The literature suggests that baccalaureateprepared nurses are socialized to expect autonomy and therefore tend to be more dissatisfied than other nurses when they perceive a lack of autonomy in their work environment (Kramer, 1974). It was suggested that baccalaureate education may foster professional autonomy by shaping nurses' perceptions of initiative and responsibility and conceding rights to patients (Pankratz \& Pankratz, 1974; Murray \& Morris, 1982). A comprehensive literature review, however, suggests that professional socialization of nurses may be hampered by ambiguity, lack of autonomy, and the com- 
peting demands of the work setting and other professionals (Conway, 1983).

\section{The Nurse-Patient Relationship}

How much latitude nurses have, are allowed, or would be willing to take in functioning as responsible professionals also is a part of the nurse-patient relationship. The area of patients' rights focuses on how much latitude patients have or are allowed with respect to knowing about and participating in their own care and treatment. Thus the question is not only how much freedom nurses see for themselves, but how much they allow their patients. It is assumed that nurses can be more valuable to patients as they use their autonomous role to become patient advocates.

\section{Nurses' Role in Health Care Delivery}

Perceived autonomy also influences nurses' ability to function as professional colleagues in the larger health care delivery environment. As long as they have a high level of dependency in relationship to physicians and hospital administrators, they will have difficulty attaining autonomy in patient care, economic security, and professional status (Janik, 1984).

Diminished autonomy occurs in varying degrees and for various lengths of time. Lack of autonomy imposed by work settings and other professionals has been documented repeatedly. The rigidly defined authoritarian organization of hospitals is a constraint on staff nurse autonomy (Katz, 1969). High levels of perceived autonomy can be related to high nurse:patient ratios, greater control over staffing, and flexible supervisory arrangements (Lewandowski \& Kramer, 1980). Nurses' sense of personal efficacy is linked to their relationship with their head nurses (Alexander, Weisman, \& Chase, 1982). Whether perceived autonomy is a product of the work setting and its organizational features or whether nurses who possess greater independence choose to work in more autonomous settings remains to be determined.

The present study was designed to measure autonomy of nurses with different educational preparation who practice in different work settings. Since autonomy is a complex phenomenon of adult and professional development with many contributing variables (Figure 1), differences based on age and years of employment in nursing were also examined.

On the basis of previous research, it was expected that nurses from baccalaureate programs and those practicing in community health settings would perceive themselves as more autonomous. Age and years of work experience were not expected appreciably to alter perceptions of autonomy.

\section{METHODS \\ Definitions of Terms}

In this study autonomy is defined as a personal liberty of action, that state in which an individual charts and is capable of following the course of his or her own actions in accord with self-determined plans (Fromer, 1981). Autonomy is the amount of discretionary control the individual has over the performance of actions in the course of practice. It is a condition of practice claimed or aspired to by the completely socialized professional (Conway, 1983).

\section{Sample}

Community health nurses with baccalaureate nursing degrees were identified as one subsample warranting study. Two additional subsamples were selected for comparison purposes: registered nurses completing the 


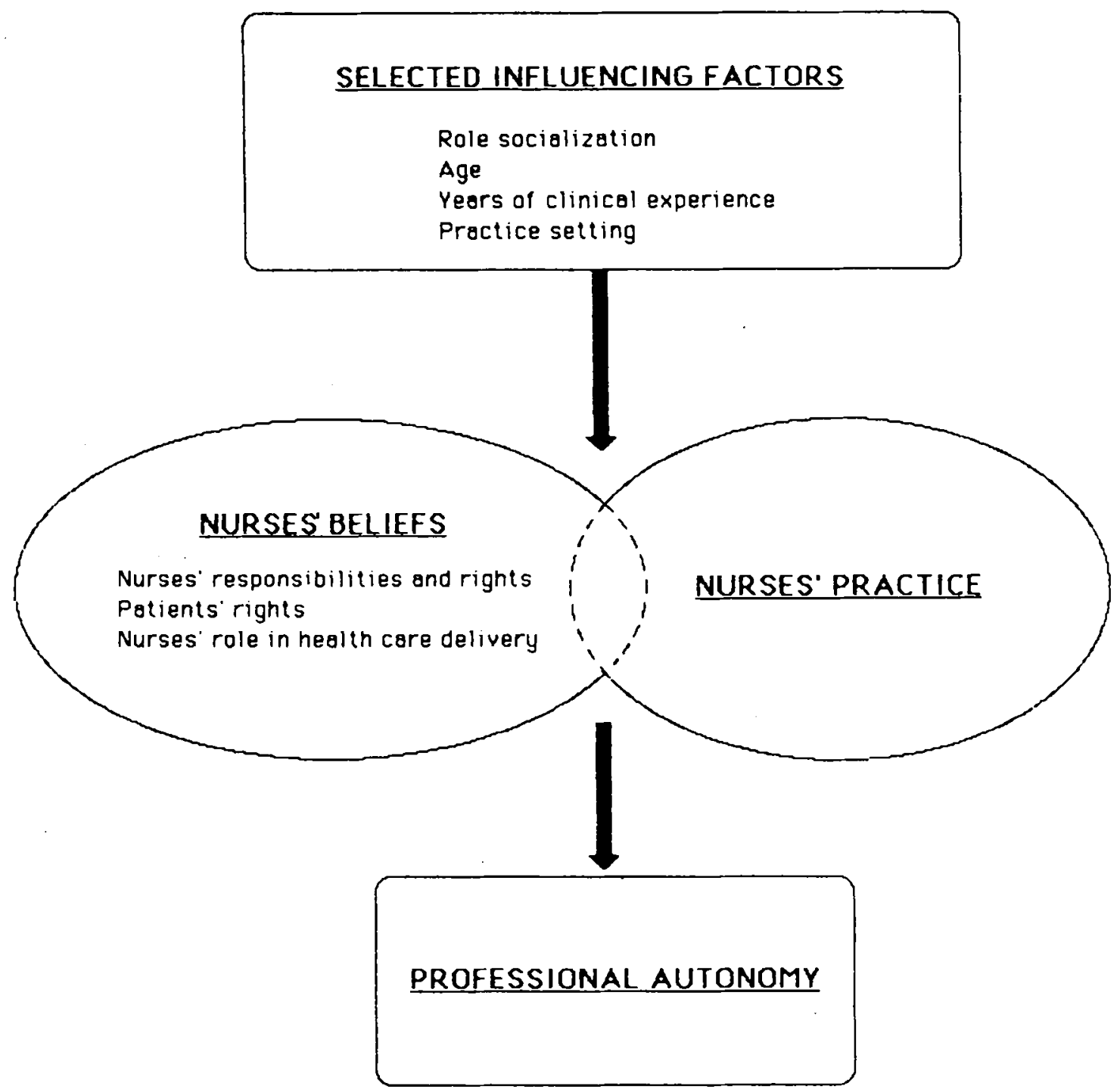

Figure 1. Professional autonomy: a conceptual framework.

first clinical practicum in a baccalaureate nursing program and senior-level generic nursing students at completion of both the baccalaureate program and the community health practicum. The latter group had essentially completed the socialization processes for both the program and the speciality practicum. Registered nurses enrolled in their first practicum in a baccalaureate nursing program had work experience, as had the community health nurses, but they were not socialized through a baccalaureate program or the speciality community health practicum, as were the senior-level generic nursing students. Students (SNs), registered nurse students (RNs), and community health nurses 
(CHNs) within the immediate geographic area were contacted. Participants included all 14 of the SNs in two community health practicums in the nearby baccalaureate nursing program; 18 (94\%) CHNs with baccalaureate nursing degrees from a nearby official agency, and $13(86.6 \%)$ registered nurses enrolled in their first nursing practicum in the same baccalaureate nursing program

\section{Procedure}

A standardized procedure was used to identify subjects and collect data. Cross-validity checks using other scales or observations were not done. All responses were treated with confidentiality. Birth dates, not names, were used for identification purposes. Subjects were informed that their participation would not affect grades or evaluations in their work setting. Table 1 summarizes the demographic variables of age and years of employment in nursing for the 45 participants.

\section{Instrument}

The nursing autonomy and patients' rights questionnaire (Pankratz \& Pankratz, 1974) is a 47-item self-administered questionnaire. As a result of the Pankratz's initial study, three dimensions were derived by factor analysis: nurses' autonomy, patients' rights, and nurses' rejection of traditional role limitations. All items on the revised questionnaire were scored on a five-point Likert-type scale ( 1 = strongly agree, 5 = strongly disagree).

The nursing autonomy dimension measured nurses' perception of their rights, taking initiative, and assuming responsibility. Representative items included, "I would feel free to try new approaches to patient care without the permission of an administrative nurse" and "I do not answer too many of the patient's questions because the doctor may have another plan in mind." The second dimension, patients' rights, referred to the nurse-patient relationship and measured nurses' feelings about conceding rights to patients; for example, "I feel the patient has a right to refuse care" and "I feel I should suggest to patients, family, and doctors any community resources I know are available." The last dimension, rejection of traditional role limitations, measured nurses' willingness to become involved with patients' personal problems and their relationship with other health professionals, particularly physicians. Representative items were, "I have fulfilled my responsibility when I report a condition to a doctor" and "If I requested a psychiatric consultation for a patient, I would feel out of bounds."

\section{Validity}

The instrument had content and face validity in two respects. First, the questionnaire included a reasonable representative sampling of the domain of conflicts in nursing autonomy, and second, the three dimensions em-

TABLE 1. Age and Years of Employment in Nursing

\begin{tabular}{|c|c|c|c|c|c|c|}
\hline \multirow[b]{2}{*}{ Subsample } & \multicolumn{3}{|c|}{ Age } & \multicolumn{3}{|c|}{ Years of Employment } \\
\hline & Range & $\overline{\mathrm{x}}$ & SD & Range & $\overline{\mathrm{X}}$ & $\mathrm{SD}$ \\
\hline $\begin{array}{l}\mathrm{CHN}(n=16) \\
\mathrm{RN}(n=18) \\
\mathrm{SN}(n=14)\end{array}$ & $\begin{array}{l}25-60 \\
21-50 \\
21-28\end{array}$ & $\begin{array}{l}36.94 \\
31.46 \\
22.71\end{array}$ & $\begin{array}{l}9.23 \\
8.99 \\
1.98\end{array}$ & $\begin{array}{c}3-23 \\
1-11 \\
0\end{array}$ & $\begin{array}{r}10.86 \\
6.06 \\
-\end{array}$ & $\begin{array}{c}6.45 \\
3.62 \\
-\end{array}$ \\
\hline
\end{tabular}


TABLE 2. Means and Standard Deviations

\begin{tabular}{|c|c|c|c|c|c|c|}
\hline \multirow[b]{2}{*}{ Subsample } & \multicolumn{2}{|c|}{ Autonomy } & \multicolumn{2}{|c|}{ Patients' Rights } & \multicolumn{2}{|c|}{ Role } \\
\hline & $\overline{\mathrm{X}}$ & SD & $\overline{\mathrm{X}}$ & $\overline{S D}$ & $\overline{\mathbf{x}}$ & SD \\
\hline $\begin{array}{l}\mathrm{CHN}(n=18) \\
\mathrm{RN}(n=13) \\
\mathrm{SN}(n=14)\end{array}$ & $\begin{array}{r}100.28 \\
89.77 \\
93.93\end{array}$ & $\begin{array}{l}6.59 \\
7.03 \\
5.50\end{array}$ & $\begin{array}{l}62.39 \\
58.08 \\
60.86\end{array}$ & $\begin{array}{l}3.94 \\
5.92 \\
4.74\end{array}$ & $\begin{array}{l}52.61 \\
48.62 \\
48.14\end{array}$ & $\begin{array}{l}3.47 \\
4.63 \\
3.68\end{array}$ \\
\hline
\end{tabular}

bodied the major facets of autonomy, which served as the study's conceptual framework.

\section{Reliability}

Reliability testing by Pankratz and Pankratz rendered the following coefficients of internal consistency: 0.93 for nursing autonomy, 0.81 for patients' rights, and 0.81 for rejection of traditional role limitations.

\section{Data Analysis}

All data for the present study were treated as group data and no attempt was made to identify single responses. Guidelines developed by Pankratz and Pankratz were used to score and interpret questionnaire responses. Data were analyzed using the MIDAS and OSIRIS statistical packages operating under the Michigan Terminal System.

\section{RESULTS}

Table 2 gives the means and standard deviations for the three subsamples on the three dimensions of the questionnaire. Scores on nursing autonomy ranged from 82 to 114 , with a sample mean of $95.27(\mathrm{SD}=7.68$ ). Analysis of variance (Table 3 ) indicated that the subsample means differed significantly (F $(2,42)=10.60 ; p<0.005)$. Post hoc comparisons using the Scheffe's test indicated that this overall statistical significance was due to specific differences in means among the three subsamples. Indeed, pairwise comparisons yielded significant vari-
TABLE 3. Results of Analysis of Variance: Nursing Autonomy

\begin{tabular}{lrrrll}
\hline Source & df & \multicolumn{1}{l}{ ss } & \multicolumn{1}{c}{ ms } & F & $P$ \\
\hline Among & 2 & 869.95 & 434.98 & 10.60 & 0.0002 \\
Within & 42 & 1722.80 & 41.02 & & \\
Totals & 44 & 2592.80 & & & \\
\hline
\end{tabular}

$\mathrm{df}=$ degrees of freedom; ss = sum of squares; $\mathrm{ms}=$ mean square; $\mathrm{F}=$ variance ratios; $P=$ probability.

ance ratios (F) when comparing $\mathrm{RNs}$ and CHNs $(F(1,30)=20.32 ; p<0.005)$. Similarly, a comparison between $\mathrm{CHNs}$ and $\mathrm{SNs}$ indicated that the means were significantly different $(F(1,31)=7.74 ; p<0.01)$. In contrast, pairwise comparison of $\mathrm{RNs}$ and SNs indicated similarity of means (F $(1,26)$ $=2.84 ; p>0.05$ ).

For patients' rights (Table 4), scores ranging from 47 to 70 were obtained, with a sample mean of $60.67(\mathrm{SD}=5.04)$. In a comparison of the three subsamples on this dimension, no differences existed ( $F(2,42)$ $=3.03 ; p>0.05$ ).

Note, however, that statistical significance was nearly attained as the probability level equaled 0.059 . Because of the lack of sta-

TABLE 4. Results of Analysis of Variance: Patients' Rights

\begin{tabular}{lrrlll}
\hline Source & \multicolumn{1}{c}{$d f$} & \multicolumn{1}{c}{ ss } & ms & F & $P$ \\
\hline Among & 2 & 141.08 & 70.54 & 3.03 & 0.059 \\
Within & 42 & 976.92 & 23.26 & & \\
Totals & 44 & 1118.00 & & & \\
\hline
\end{tabular}


tistical significance, no pairwise comparisons across dimensions were performed.

Scores on the rejection of traditional role limitations dimension ranged from 42 to 60 , with a sample mean of $50.07(\mathrm{SD}=4.35)$. Analysis of variance comparing $\mathrm{RNs}, \mathrm{CHNs}$, and SNs (Table 5) indicated rejection of the null hypothesis of equality of subsample means (F $(2,42)=6.45 ; p<0.005)$. Subsequent pairwise comparisons suggested that differences in subsamples existed mainly between CHNs and each of the other subsamples (Figure 2). Indeed, differences were significant between $\mathrm{RNs}$ and $\mathrm{CHNs}$ ( $\mathrm{F}(1,30)$
TABLE 5. Results of Analysis of Variance: Rejection of Traditional Role

\begin{tabular}{lrllll}
\hline Source & df & ss & ms & F & $P$ \\
\hline Among & 2 & 195.73 & 97.87 & 6.45 & 0.004 \\
Within & 42 & 637.07 & 15.17 & & \\
Totals & 44 & 832.80 & & & \\
\hline
\end{tabular}

$=7.95 ; p<0.01)$ and between SNs and CHNs (F $(1,31)=10.37 ; p<0.005)$. No statistical significance was noted in a comparison of RNs and $\operatorname{SNs}(F(1,26)=0.10$; $p>0.05$ ).

In addition, two significant correlations

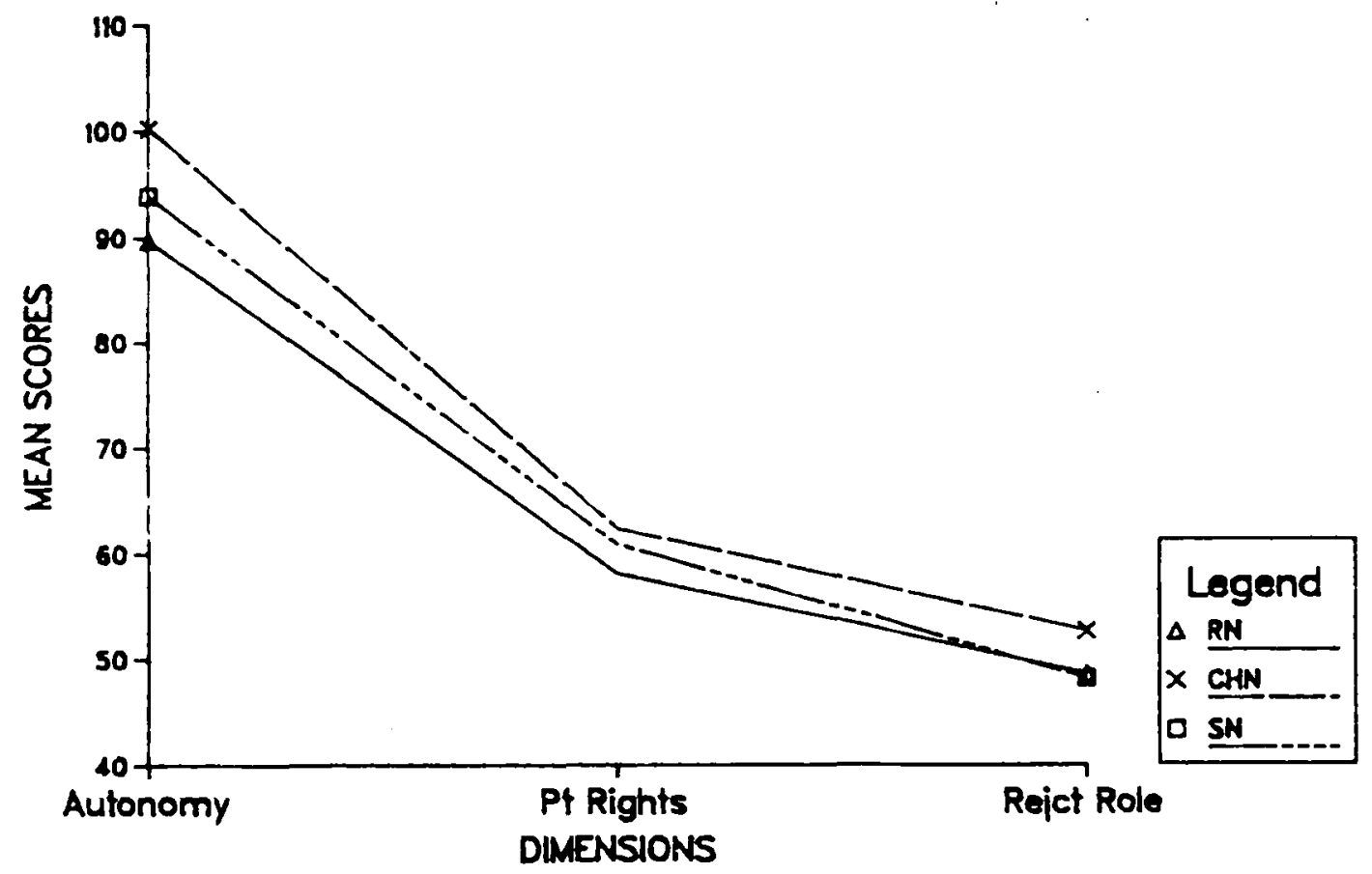

Figure 2. Comparison of facets of autonomy to the derived autonomy dimensions of Pankratz and Pankratz and concepts of nursing leaders. 
were noted. A significant negative correlation $(r=-0.49 ; p<0.05)$ was observed between CHNs' ages and their scores on nursing autonomy. A significant correlation ( $r=0.60 ; p<0.05$ ) was observed between RNs' years of employment in nursing and their nursing autonomy scores.

\section{DISCUSSION}

The major finding of this study was the difference in mean scores on the nursing autonomy dimension between community health nurses and both the registered nurses and student nurses. While this difference suggests that community health nurses may be more autonomous, it provides little information regarding factors that contribute to the difference. Since all community health nurses held baccalaureate nursing degrees, the impact of baccalaureate nursing education on the nurses' beliefs regarding professional autonomy must be considered. If baccalaureate nursing education promotes beliefs of professional autonomy, it would seem reasonable that the mean score for the nursing students would be similar to that for the community health nurses, but it was not. If the impact of baccalaureate education is questionable, perhaps years of employment in nursing is a significant factor. This result, however, was evident for registered nurses only and not for community health nurses. It is conceivable that nursing practice and years of employment in nursing, regardless of the educational program, promote professional autonomy. For community health nurses, a combination of factors is likely to exist, for example, the baccalaureate nursing program, the community health setting itself, and the personal characteristics of the nurses who pursue this specialty.

With regard to the mean scores on the patients' rights dimension, the emphasis placed in community health nursing on patient advocacy requires consideration. Community health nurses are frequently required to intervene on behalf of patients, to assist clients in identifying health care alternatives, and to promote selection of alternatives most aligned with the patients' values and beliefs. Since there was no statistical significant difference between community health nurses and student nurses, we can only speculate that baccalaureate education may promote stronger beliefs about patients' rights than alternative programs. We also suggest that the practice setting may be a major factor affecting nurses' beliets about patients' rights.

Analysis of the mean scores of the three subsamples for the rejection of traditional role limitations dimension suggested that setting is probably a major contributing factor. Community health nurses practice primarily under the direction and guidance of other nurses, not health professionals of other disciplines. Individual community health nurses assume responsibility for time and caseload management; emphasis is on nursing management. Registered nurses in other settings, such as acute or long-term care, implement both medical and nursing management of their patients. The opportunity to alter the traditional role tends to be less available in these settings due to approaches in health care management and financial reimbursement mechanisms. This may also be true for registered nurses practicing in many voluntary community health settings, for example, the visiting nurse service or other home care agencies.

This study supported results of Pankratz and Pankratz (1974) in noting that age is not a factor in autonomy; however, the negative correlation between age and nursing autonomy for community health nurses was puzzling. Does this suggest that there is a plateau 
or limit regarding the scope of autonomous beliefs? Why was this finding only apparent for community health and not registered nurses? To what extent does socialization through the educational program and current nursing beliefs alter one's beliefs about professional autonomy?

In addition, this study supported previous findings (Pankratz \& Pankatz, 1974; Murray \& Morris, 1982) that baccalaureate education influences nurses' perceptions toward taking initiative and assuming responsibility.

\section{Further Research}

Several avenues were suggested for future research. Comparisons of perceptions of nurses by educational preparation or work setting should be pursued; for example, nurses with generic baccalaureate nursing degrees employed by general hospitals and community health nurses who differ in their nursing education preparation but have similar job responsibilities. A corresponding question for study is whether perceptions of autonomy remain the same as student nurses are professionally socialized or differ over time? If we believe that nursing curricula foster beliefs about nursing autonomy, patients' rights, and rejection of traditional role limitations, it becomes essential to identify the specific educational approaches that promote these outcomes. It is also imperative that the effectiveness of these approaches be evaluated.

\section{Study Limitations}

This study had several limitations. (1) Because perceived beliefs may differ from actual performance, a comparison of the two would further strengthen the validity of selfreports as they pertain to professional autonomy. (2) Since the questionnaire was originally designed for use by nurses em- ployed in the hospital setting, item review and alteration are necessary to render the tool appropriate for nurses across specialties and practice settings. (3) It must also be acknowledged that the sample in this study was small and that a nonrandom selection process was used. Therefore any implications drawn must be viewed cautiously and tentatively. (4) As indicated previously, autonomy involves a network of reciprocal effects-age, years of work experience, practice setting, and role socialization. The exact nature of these effects would be best revealed in longitudinal studies using multiple regression techniques for data analysis.

\section{ACKNOWLEDGMENTS}

The authors express their appreciation to the nurses who participated in this study and to Anita Turner, director of the Bureau of Nursing, Ingham County Health Department, Lansing, Michigan, for her support and encouragement.

\section{REFERENCES}

Ahad, M. A. (1981). Evolution of nursing science: Implications for nursing world wide. Sigma Theta Tau - Image, 13, 56-59.

Alexander, C. E., Weisman, C. S., \& Chase, G. A. (1982). Determinants of staff nurses' perceptions of autonomy within different clinical contexts. Nursing Research, 31(1), 48-52.

American Nurses' Association (1976). Code for nurses with interpretive statements. (ANA Publication Code No. G-56.) Kansas City, MO.: Author

Cogan, M. (1953). Toward a definition of profession. Harvard Educational Review, 23, 3350.

Conway, M. E.(1983). Socialization and roles in nursing. In H. Werley \& J. J. Fitzpatrick (Eds.). Annual review of nursing research (Vol. 1). New York: Springer.

Eldridge, I, \& Levi, M. (1982). Collective bar- 
gaining as a power resource for professional goals. Nursing Administration Quarterly, 6(2), $29-40$.

Freidson, E. (1970). Professional dominance. New York: W. W. Norton.

Fromer, M. J. (1981). Paternalism in health care. Nursing Outlook, 29(5), 284-290.

Greenwood, E. (1957). Attributes of a profession. Social Work, 2, 44-55.

Gilligan, C. (1982). In a different voice. Cambridge: Harvard University Press.

Janik, A. (1984). Power base of nursing in bargaining relationships. Image: Joumal of Nursing Scholarship, 16(3), 93-96.

Johnson, T. J. (1972). Professions and power. London: Macmillan

Kalisch, B. J., \& Kalisch, P. (1982). Politics of nursing. Philadelphia: J. B. Lippincott.

Katz, F. E. (1969). Nurses. In A. Etzionni (Ed.). The semi-professions and their organization. New York: Free Press.

Kramer, M. (1974). Reality shock: Why nurses leave nursing. St. Louis: C. V. Mosby.

Lewandowski, L. A., \& Kramer, M. (1980). Role transformation of special care unit nurses: A comparative study. Nursing Research, 29, 170-179.

McFarland, D. E., \& Shiflett, N. (1979). The role of power in the nursing profession. Nursing Dimensions, 7(2), 1-13.

Mundinger, M. O. (1980). Autonomy in nursing. Germantown, MD: Aspen.
Murray, L. M., \& Morris, D. R. (1982). Professional autonomy among senior nursing students in diploma, associate degree, and baccalaureate nursing programs. Nursing $R e$ search, 31(5), 311-313.

Pankratz, L., \& Pankratz, D. (1974). Nursing autonomy and patients' rights; Development of a nursing attitude scale. Joumal of Health and Social Behavior, 15(3), 211-216

Parsons, T. (1954). The professions and social structure. In Essays in Sociological Theory. Glencoe, III: Free Press

Silva, M. C. (1983). The American Nurses' Association's position statement on nursing and social policy: Philosophical and ethical dimensions. Joumal of Advanced Nursing, 8, 147151.

Simms, L.M. \& Lindberg, J.B. (1978). The nurse person: Developing perspectives for contemporary nursing. New York: Harper \& Row.

Straub, C. A. (1982). An explanation of Chickering's theory and development. Unpublished doctoral dissertation, Ohio State University, Columbus, Ohio.

Styles, M. (1982). On nursing: Toward a new endowment. St Louis: C. V. Mosby.

Wilensky, H. L. (1964). The professionalization of everyone? American Joumal of Sociology, $70,137-158$. 